\title{
توظيف التقنيات المساندة لتأخير التغذية السمعية المرتدة ببرامج علاج التلعثم
}

\author{
د. يوسف محمد يوسف عيد \\ أستاذ التربية الخاصة المشارك \\ قسم التربية الخاصة، كلية التربية \\ جامعة الملك خالد المملكة العربية السعودية
}




\section{ملخص البحث}

يهدف البحث الحسالي إلى التعرف على كيفية توظيف التقنيات المسـاندة لتأخير

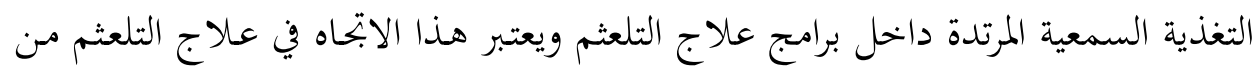

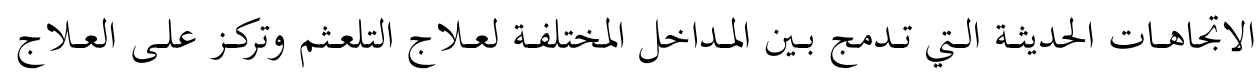

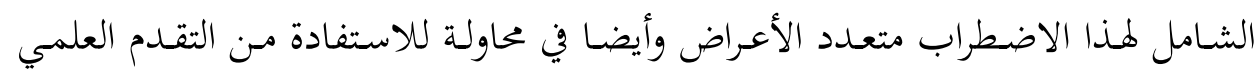

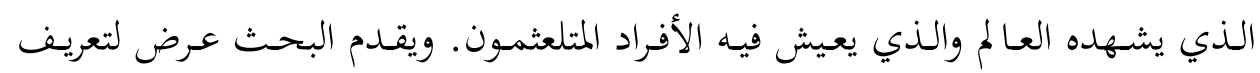
وأسباب ومراحل التلعثم وكيفية تشخيص الأفراد ذوي اضطراب التلعثم ومحتويات البرامج العلاجيـة الخاصـة بـالتلعثم وتعريف التغذية السـعية المرتدة والتقنيـات الحديثة المسـاندة

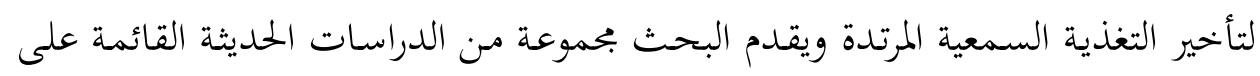

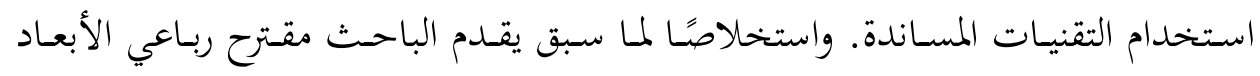

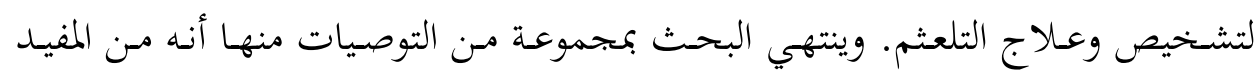

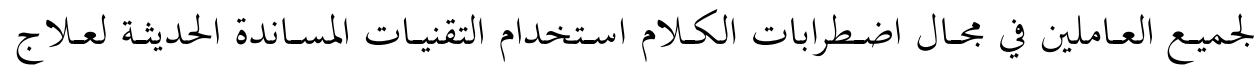




\title{
Abstract \\ Using Assistive technologies of Delayed Auditory Feedback (DAF) in Stuttering Treatment Programs
}

\author{
Dr. Yossef Mohamed Yossef Eid \\ Associate Professor \\ Special Education Department, Faculty of Education - King Khalid \\ University
}

The research aims to identify how to use techniques to support the delay of auditory feedback within the programs of the treatment of stuttering. This approach in the treatment of stuttering is one of the modern approaches that integrate the various approaches to treatment of stuttering and focuses on the comprehensive treatment of this disorder and also in an attempt to take advantage of scientific progress. The research shows a presentation of the definition and causes of stuttering and its stages of development and how to diagnose individuals with stuttering and the contents of the treatment programs, the definition of auditory feedback and the new techniques supporting delaying feedback. The research presents a series of recent studies based on the use of techniques to delay delayed feedback. In conclusion, the researcher presents a fourdimensional proposal for the diagnosis and treatment of stuttering. The research ends with a set of recommendations, including the use of modern support techniques for the treatment of stuttering. 
التلعثم أحد الاضطرابات الكلامية التي تصيب الصغار والكبار ويشفى منه نسبة كبيرة من الأطفال قبل سن السادسة بصورة تلقائية ولكن إذا استمر بعد هذا العمر يحتاج إلى التدخلات والبرامج العلاجية المتخصصة. ويطلق على التلعثم بأمريكا (Stuttering) وين إبنحلترا يطلق عليه (Stammering) وعلميًا يسمى (Dysphemia). وذكر Chesters, Mottonen, Watkins, (2018) أن التلعثم يصيب حوالي 5\% مـن الأطفال ويستمر مع البالغين بنسبة تصل إلى 1\% وعـلاج هذه النسبة مـن المصـابين البـالغين يمثل أحسد التحـديات العلاجية في بجال عـلاج اضطرابات الكلام، ولذا يتم استخدام كثير مـن التدخلات والاستعانة بالتقنيات المسـاندة الحديثة التي يثبـت بعضها النجاح مع بعض الحالات ولا يتحقق هذا النجاح لبعض التقنيات الأخرى. وهناك الكثير من الدراسات والبحوث التي تؤكد على دور التغذية السمعية المرتدة في خفض مستوى التلعثم وحـديثًا ومع استخدام المتلعثم لجهاز، أو تطبيق يقوم بتأخير الككلام بجزء من الثانية ظهر التحسن عند كثير من الحالات ولكن لم تقدم هذه التقنيات النجاح التام لكل الحالات التي استخدمت الأجهزة الخاصة بتأخير التغذية السمعية المرتدة

.(Gully, 2018)

وأشار (2018) Coleman, إلى أن التقييم والعلاج الشـامل للتعثم يسهل من دور الاخصـائيين في عـلاج جميع العوامـل المسـببة لهـا الاضطراب والتعامـل معـه بصـورة متكاملة شاملة للجوانب المختلفة والمتعددة للاضطراب، وهذه الطريقة أفضل من التركيز على خفض أعراض التلعثم الظاهرة فقط. وأوضحت العطية (2011) أن التلعثم اصطلاح أشار إلى التمتمة والفأفأة والتأتأة في الكـلام، والتلعـثم أكثر عيـوب الكـلام شـيوعًا بـين الأطفـال، وأسبابه معقـدة، ولكـن النظرية القائلة بأن أساسه ومنشأه يرجعان إلى عوامل نفسية هي أكثر النظريات العلمية

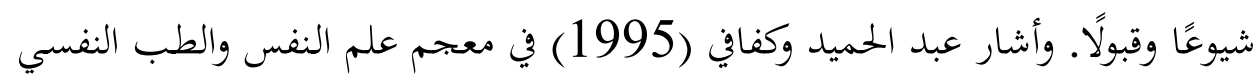


إلى التلعثم والتهتهة والتأتأه في تعريف واحدد. وأشارت برادة وصادق(2000) إلى أن اللجلجة يعبر عنها بالتهتهة والتلعثم ولكن المصطلح العلمي اللجلجة هو المفضل بين جمهيت وتهور الباحثين.

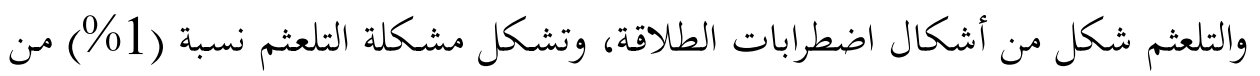
بحموع السكان. إذ يصل عدد من يعانون من التلعثم في الولايات المتحدة وحددها إلى مليكوني

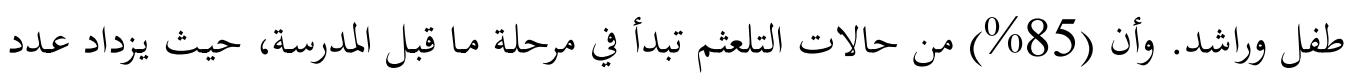
الأولاد المتلعثمين عن عدد البنات بنسبة قد تصل إلى (4-1) (Riper, 2009).

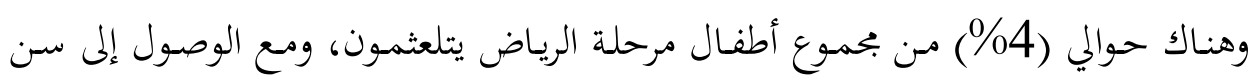

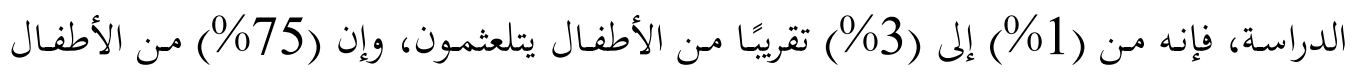

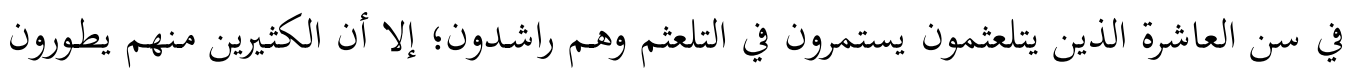

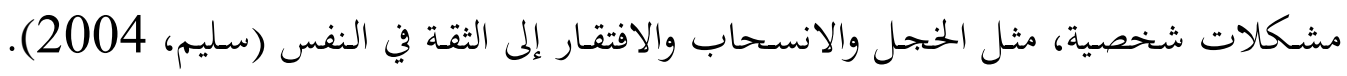
وأشار (Mash \& Wolfe, (2005 إلى أن التلعثم يبدأ لدى الأطفال منذ السنة الثانية حتى السنة السابعة وتبرز بصفة عامة عند سن الخامسة.

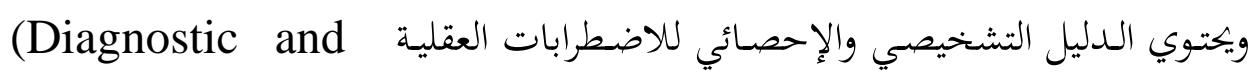
Statistical Manual of Mental Disorders, 2013) التواصل Communication Disorders ويصنفها إلى: - اضطرابات اللغة (Language Disorders). -اضطرابات صوت الكلام (Speech Sound Disorders). - التلعثم(Stuttering).

- Social (pragmatic) communication اضطرابات التواصل الاجتماعية disorder -اضطرابات التواصل غير المحددة Communication Disorders not). (Stuttering): التلعثم: specified) 
Kirk, Gallagher, Coleman and Anastasiow, عرف (2006)

الطلاقة بأها: "سريان الكلام بدون أي معوقات، أو اضطرابات". وذكروا أن التلعثم أكثر

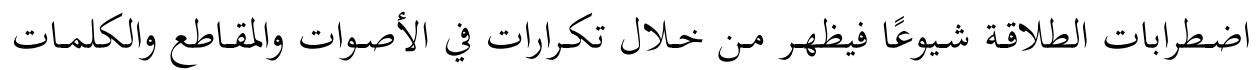
تكون مصحوبة بالقلق والتوتر وحركات تشنجية.

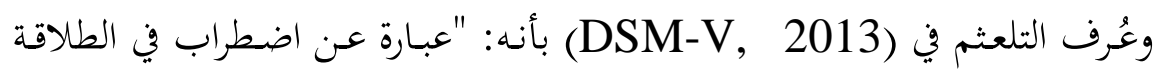

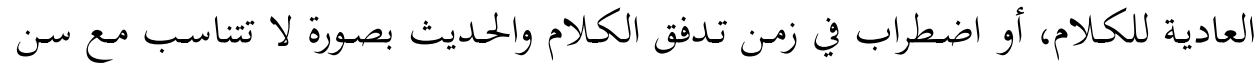
الفرد ومع مهاراته اللغوية"، ويختص التلعثم بالآتي : 1 - ترديد لصوت معين. 2- 2 - 2 إطالة في بعض الأصوات. 3- - 2 - الكلمات المتقطعة. 4- التقطيع المفاجئ للكاملام. 5-عدم نطق الكلمة والدوران والإسهاب حول معناها. 6- ترديد الكلمات خاصة الكلمات ذات المقطع الواحد. 7- إنتاج الكلمات بجهد بدني مفرط.

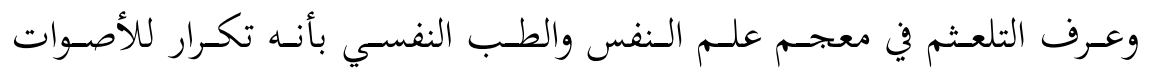

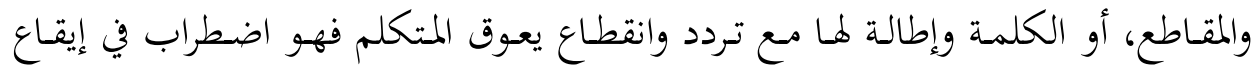

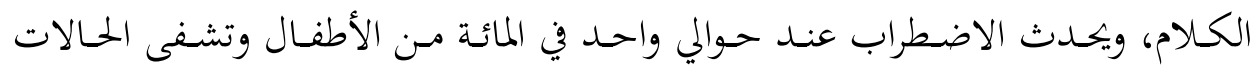

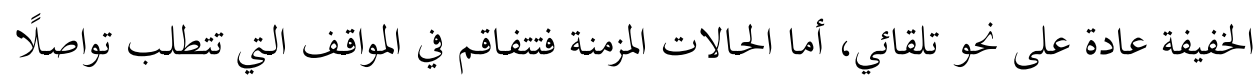
(عبد الحميد وكفافي، 1995). وتعرف باظة (2003) التلعثم بأنه: "اضطراب في إيقاع الكلام وطلاقته يتميز إما

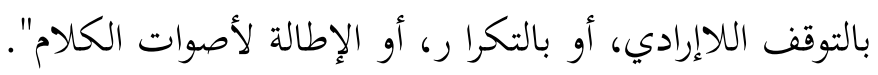


وعرف (2009) Riper, التلعثم بأنه: "اضطراب في البعد الزمني للككام، حيث ينقطع

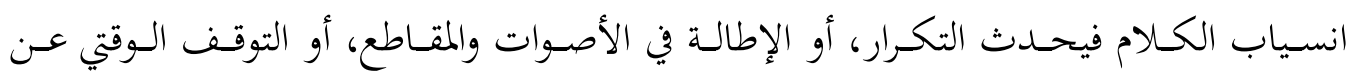

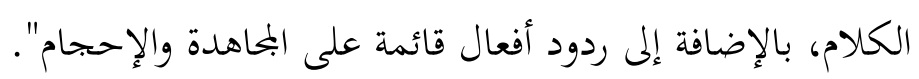

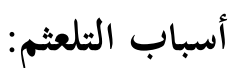

ذكر Bahadorinejad, (2012) أن التلعثم قد يحدث نتيجة ضعف في اللعاب أثناء

الككام مما يسبب تكرار غير طوعي، أو يسبب تطويل في بعض الألفاظ.

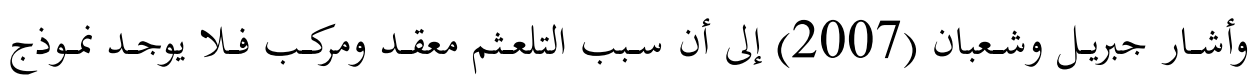

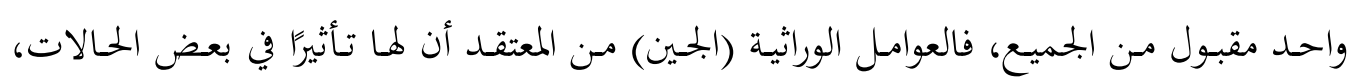

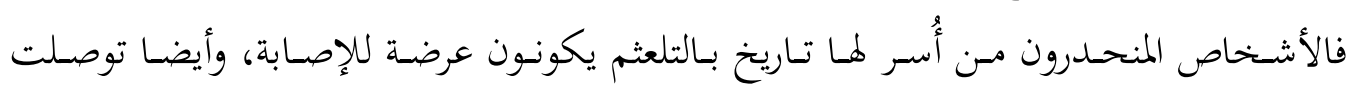

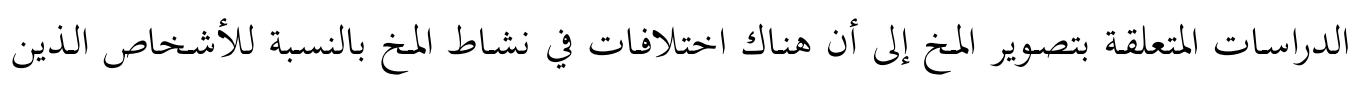
يعانون من التلعثم عند مقارنتهم بآخرين يتحدثون بطالاقة.

وأوضح Freiterg \& Karen, (2002 أن أسباب التلعثم قد ترجع إلى:

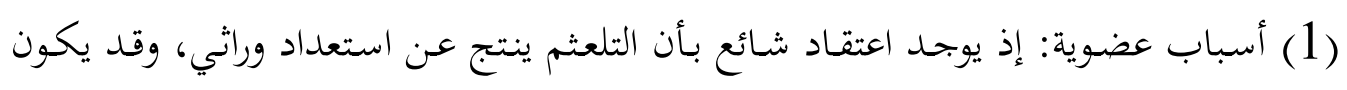

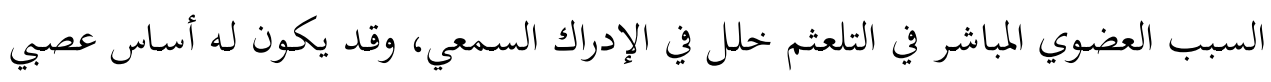

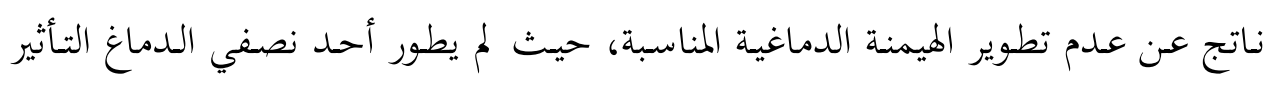

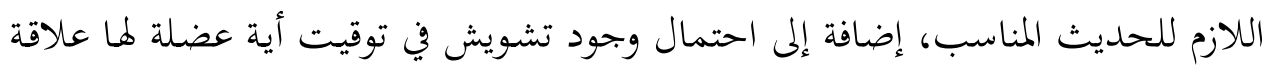

بالكلام بما في ذلك الشفاه والفم.

(2) توقعات الأبوين غير الواقعية من الطفل: تؤدي إلى ضغوطات على الأطفال ترفع من

قلقهم.

(3) قد يكون التلعثم رد فعل للضغط والتوتر الذين يعاني منهم الطفل نتيجة شروط التربية التهابية

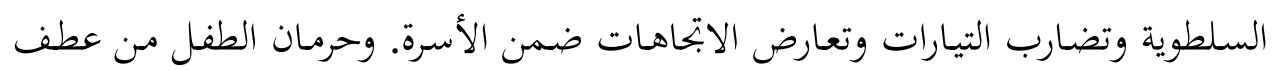

أحد أبويه، أو العيش ضمن أجواء عائلية تعيسة. 


$$
\begin{aligned}
& \text { (4) إفراط الوالدين في رعاية الطفل وإحاطته بالتدليل، مما يحرمه من التدرب على الاستقلالية }
\end{aligned}
$$

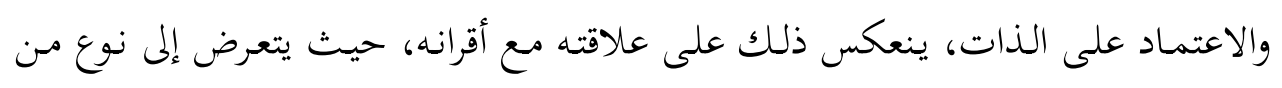

$$
\begin{aligned}
& \text { الحقد والغيرة من قبلهم. } \\
& \text { (5) قسر طفل يكتب بيده اليسرى على الكتابة بيده اليمنى. } \\
& \text { (6) الفشل في التحصيل الدراسي. }
\end{aligned}
$$

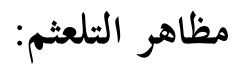

أوضح الببلاوي (2016) مظاهر التلعثم التي تظهر لدى المتلعثمين في أربعة نقاط

$$
\begin{aligned}
& \text { رئيسة وهي: } \\
& 1 \text { - الإعادة: } \\
& \text { •تكرار جزء من الكلمة مثل (ك. ك. كل يوم). }
\end{aligned}
$$

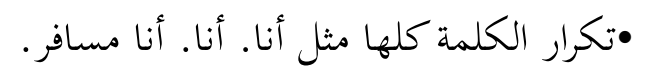

$$
\begin{aligned}
& \text { •تكرار العبارة ككل لماذا ذهبت لماذا ذهبت لماذا ذهبت. } \\
& \text { •تطويل الصوت مثل جاالي. }
\end{aligned}
$$

2- الإدخال: إقحام أصوات، أو مقاطع، أو كلمات، أو عبارات اعتراضية مثل

3- المراجعة: وذلك بأن يقطع فكرة ويرجع إلى فكرة أخرى من مثل أن يقول: أنا

$$
\text { رحت اليوم.. فين لعبتي؟ ومن ثم يكمل كلامه. }
$$

4- التطويل: ويكون ظهور هذا السلوك قليلًا في النمط، كأن يقول الطفل: أنا ئان

وأوضحت أمين (2000) مظاهر التلعثم في الآتي:

$$
\text { - Repetitions التكرار }
$$


إن التكرار يعد من أهم السمات المميزة للتلعثم، حيث إنه أحد أعراض التلعثم الأكثر

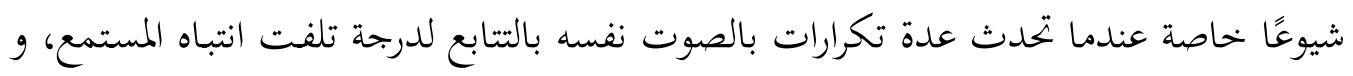
تعتبر التكرارات من الأعراض المميزة لوجود التلعثم.

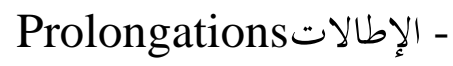

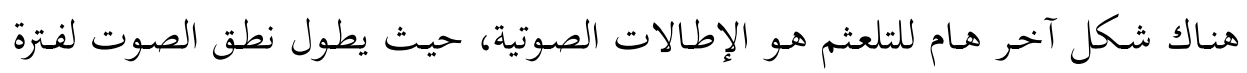

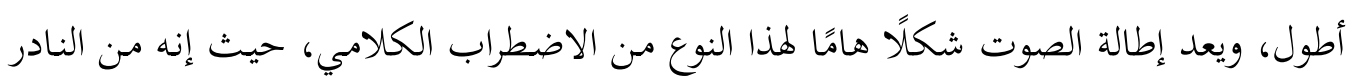

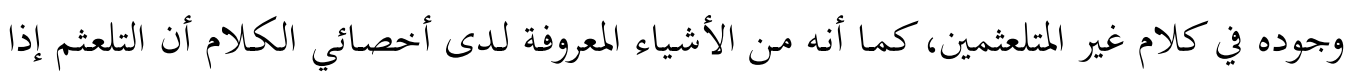

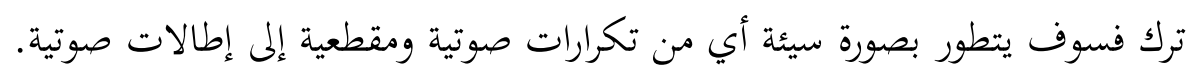

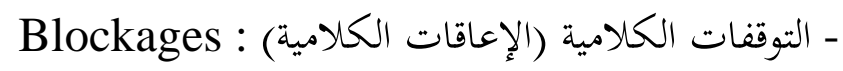

تحدث التوقفات الكلامية بسبب انفلاق ما في مكان في الجهاز الإنات الصوتي تؤدي إلى إعاقة

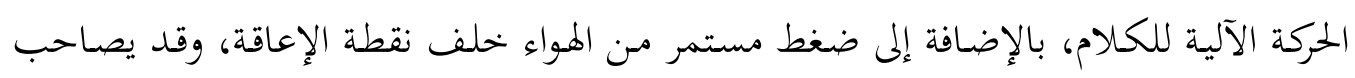

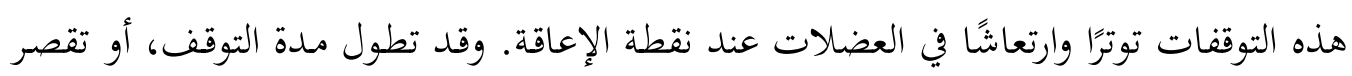

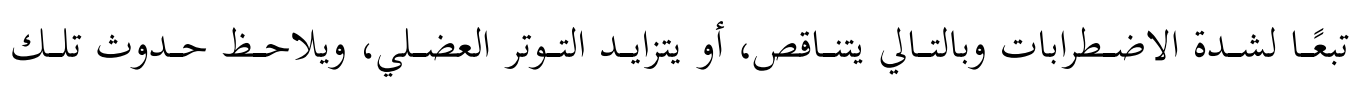
الإعاقات بصورة متكررة في بداية نطق العبارة، أو الكلمة.

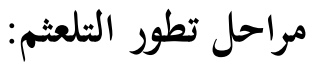

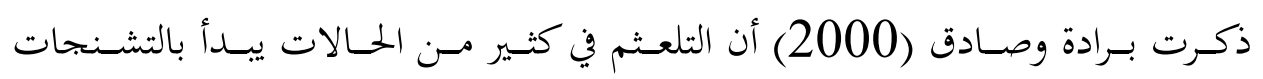

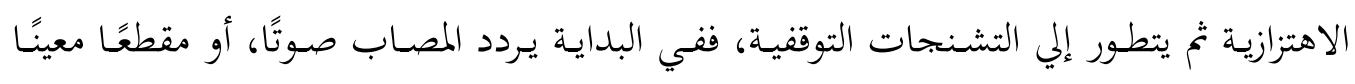

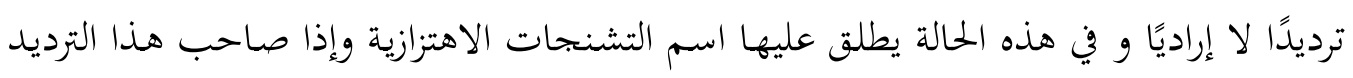

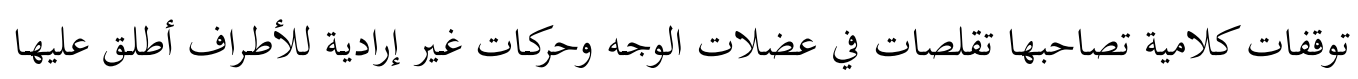

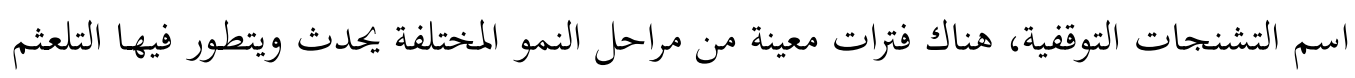

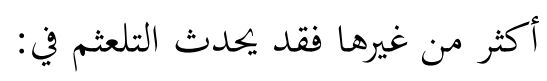


(1) ما بين 2.5 - 4 سنوات وهي الفترة التي تنمو فيها اللغة نموًا سريعًا، فالتردد منتشر بين

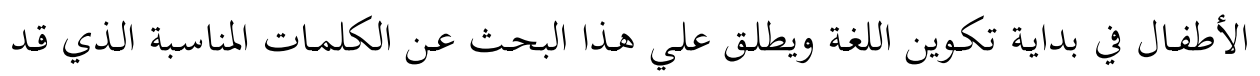
يظهر فيها التردد والتكرار "بالتلعثم الفسيولوجي".

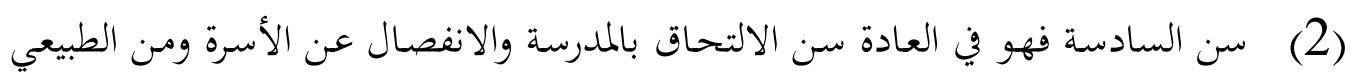

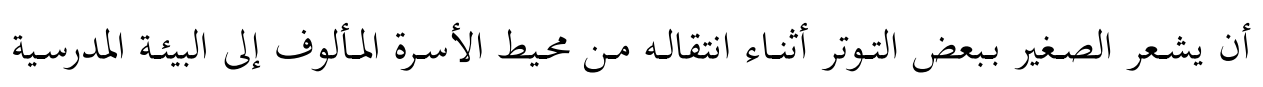
الغريبة عليه. سن البلوغ وهي الفترة التي يشعر فيها المراهق بالقلق نتيجة للتغيرات التي تطرأ عليه.

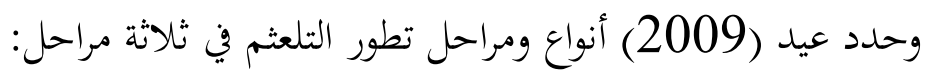

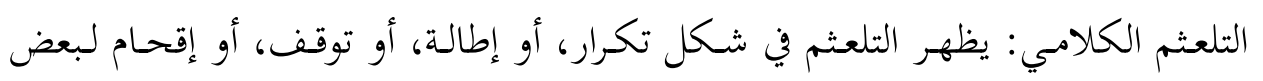

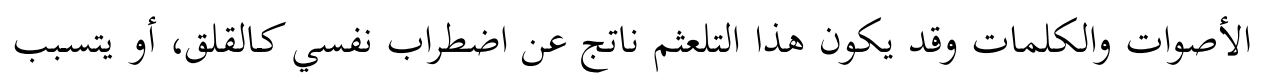
في ظهور هذا القلق وقد يكون وراثي، أو قد يكون مكتسب من البيئة المحيطة.

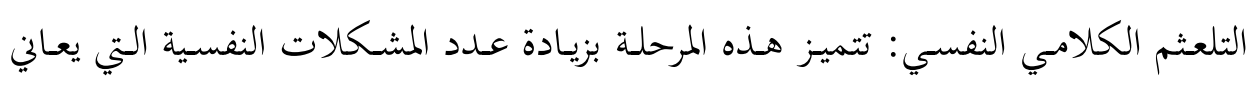

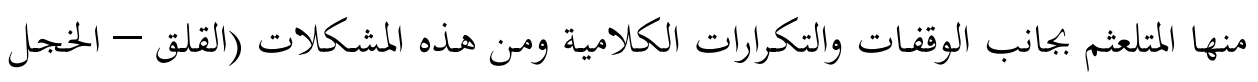
- نقص تقدير الذات - الاكتئاب - الانطواء والانسحاب).

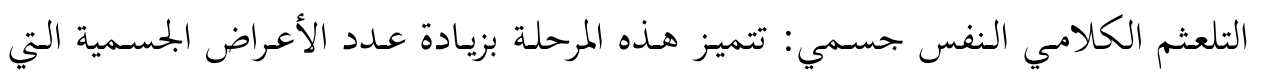

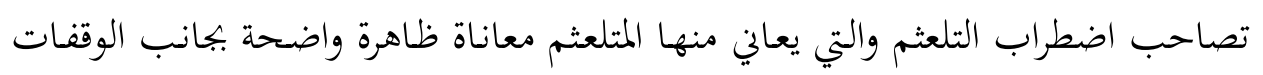
والتكرارات مع زيادة حدة المشكلات النفسية المختلفة.

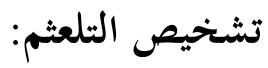

لقـد حـد الشتصص(1997) إجـراءات تشخيص التلعثم في الكـلام على النحو التالي: ملاحظة كلام الطفل أثناء حديثه مع الوالدين والأخوة، وتحميع الملاحظات إحراء تلفئ حول: (1) نوع التلعثم. (1) ملاحي. (2) مدى معاناة الطفل من التوتر والانفعال. 


$$
\text { (4) الخالة الصحية ورد الفعل حيال الاضطراب. }
$$

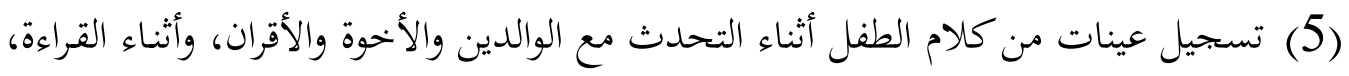

$$
\text { وتحليل ذلك. }
$$

(6) تكرار هذه الإجراءات في مواقف مختلفة في المنزل، والمدرسة، وذلك بهدف تحديد الظروف

التي يحدث فيها التلعثم بالضبط وبالتالي يتم التركيز عليها أثناء إعداد البرنامج العلاجي. ودمدي.

وذكر الفرماوي (2006) أن تشخيص اضطراب التلعثم يعتمد على الإجراءات التالية:

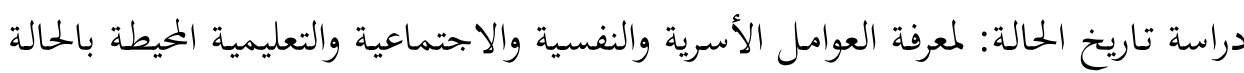

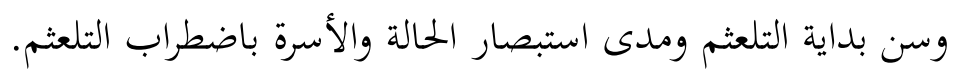

(2) الفحص الكلينكي: يتم ذلك لـدى طبيـب مختص لمعرفة مـدى سلامة أعضـاء النطق

$$
\text { والكلام والجهاز العصبي. }
$$

استخدام اختبارات اللغة: التي تشمل أبعادا لطلاقة الكلام، أو استخدام أي مـ قوائم

$$
\text { الملاحظة الخاصة باضطرابات التواصل لتحديد مظاهر التلعثم لدى الحمالة. }
$$

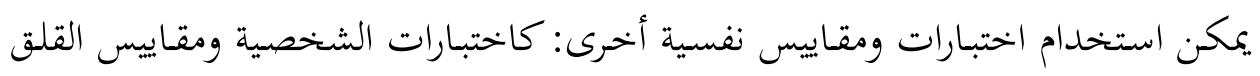

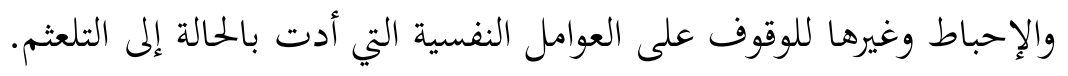

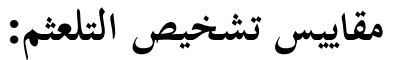

(1) بطارية كلامية نفسية إعداد عيد(2010) وتشتمل هذه البطارية على أربعة اختبارات وهي اختبار تشخيص التلثم واختبار تشخيص القلق لدى المتلعثمين واختبار تشخيص الخجل لدى المتلعثمين واختبار تقدير الذات لدى المتلعثمين.

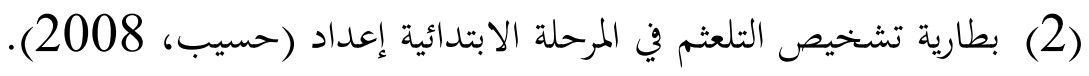

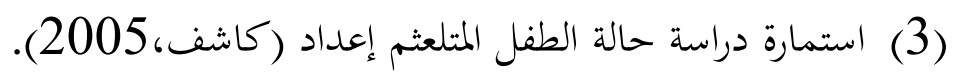


(4) استمارة قياس معدل التلعثم إعداد (Hamaguchi,2001) في (كاشف، (2005) وتتكون هذه الاستمارة من أربعة أجزاء (معدل التكرار - السلوكيات الحركية المصاحبة استجابات التجنب - حساب معدل التلعثم). (5) أداة قياس شدة التعثم (البهاص، 2005).

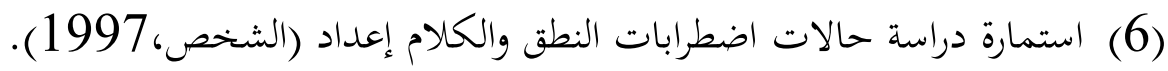

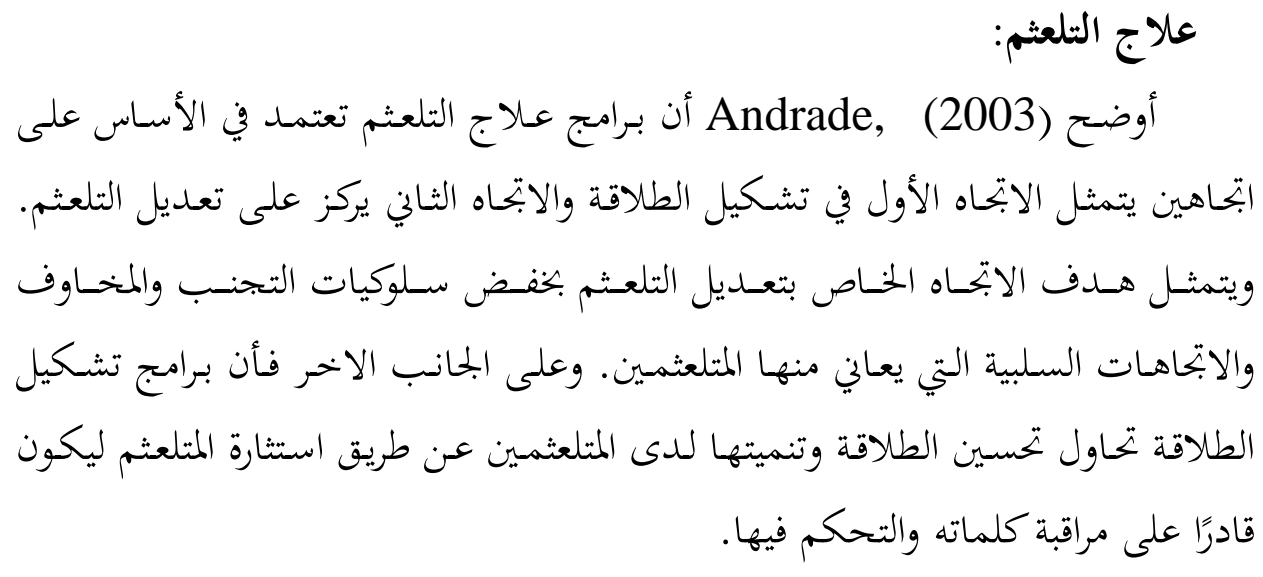

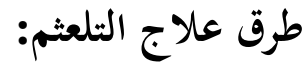

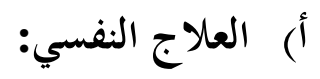

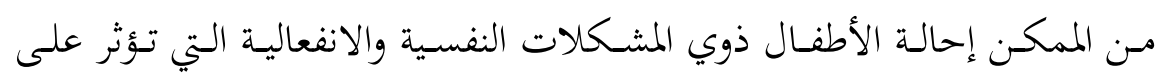

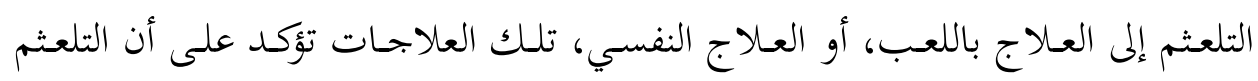

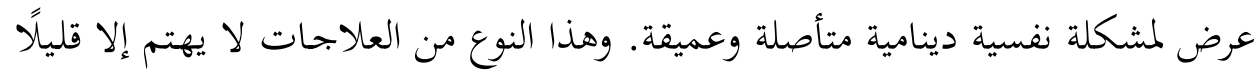
بالتلعثم في حد ذاتما، وإنما يركز على المسايرة النفسية للطفل والحيل الدفاعية واضطرابات الشخصية والقلق، وبعض المشاعر السلبية الأخرى والعلاقات البينشخصية. ويرى أنصار

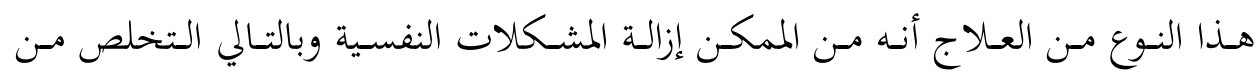
أعراض التلعثم (Bloodstein, 2007). 


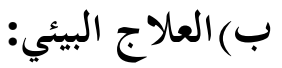

هو إجراء علاجي يركز على المتغيرات التي تجرى في بيئة الطفل والتي يعتقد أها تساهم في

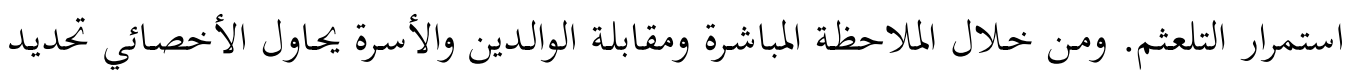
تلك العوامل وتغيير بيئة الطفل حتى تنخفض العوامل التي تؤدي إلى استمرار التلعثم، أو تزول

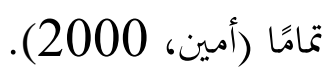

\section{ج) العلاج بالتفاعل اللفظي بين الطفل والوالدين:}

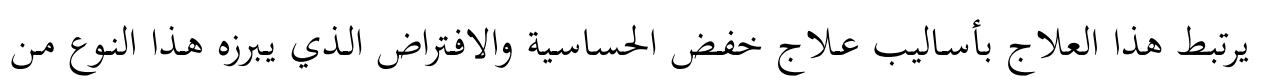

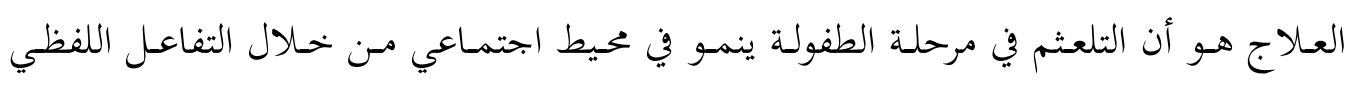

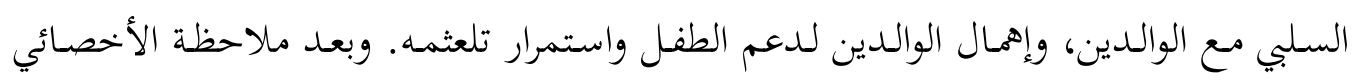

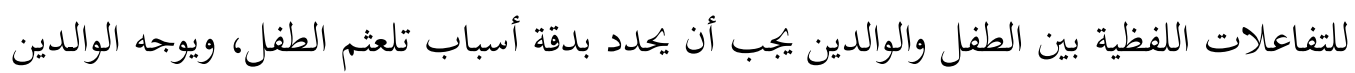

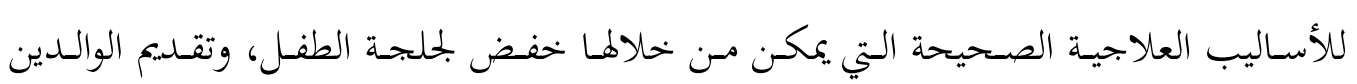

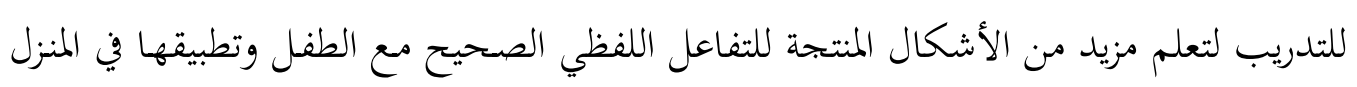

.(Kalinowski, 2006)

$$
\text { د) التدريب على الاسترخاء: }
$$

يتضمن هذا الأسلوب تدريب الطفل على الاسترخاء أثناء الكلام، ويلزم هنا معرفة كيفية

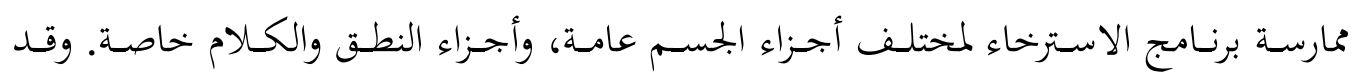

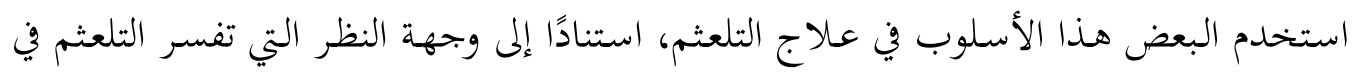

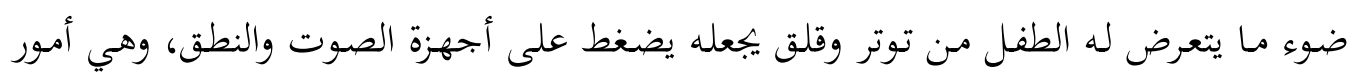

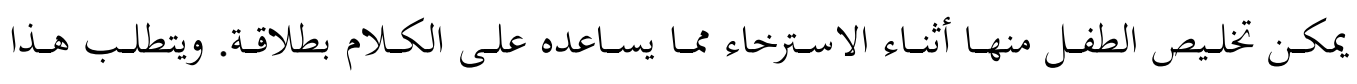
الأسلوب تدريب الطفل جيدًا على ضبط النفس، وتعلم الاسترخاءكي يستطيع تعميم نتائج

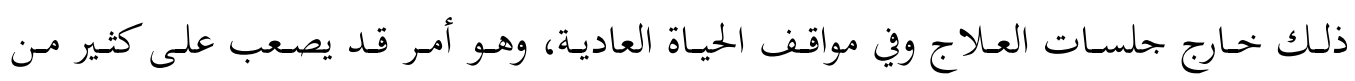
الحالات (الشخص، 1997).

هـ العلاج السلوكي لتشكيل الطلاقة (1) : Fluency Shaping Therapy 
منذ عدة سنوات من تأثيرات النظرية التشخيصية للتلعثم تم بحنب العمل مباشرة

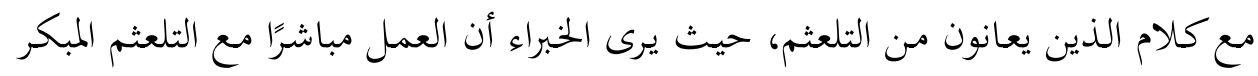

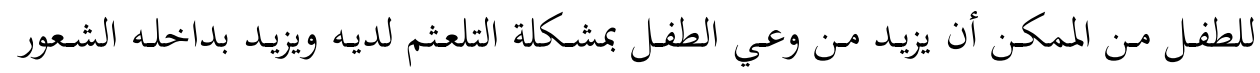

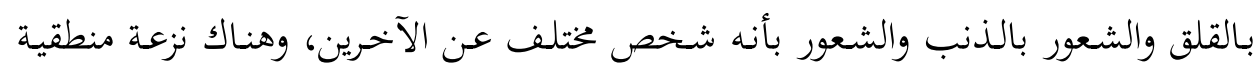
نهو هذه الفكرة وخصوصًا عندما يركز العلاج المباشر على التلعثم وتقبلها وضبطها .(Ward, 2006)

يهـدف العلاج بتشكيل الطلاقة إلى تعليم الطفل المتعالج بعض الفنيات يستطيع

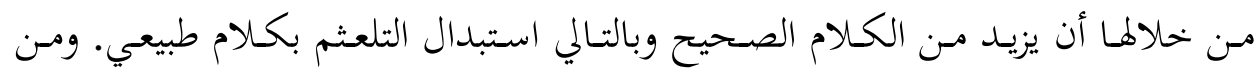

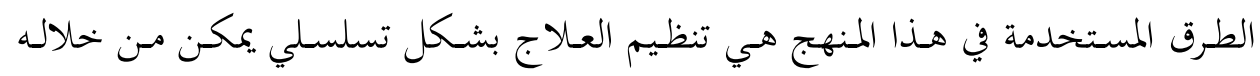

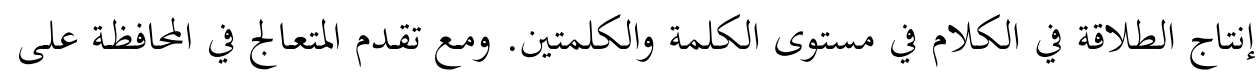

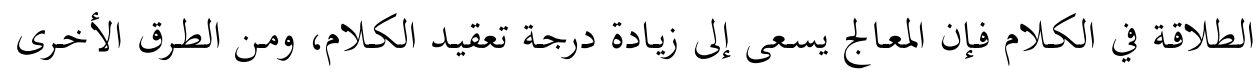

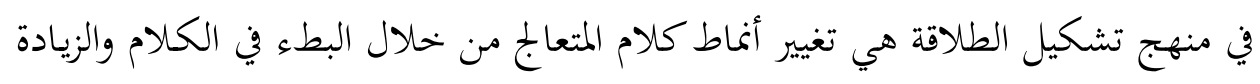

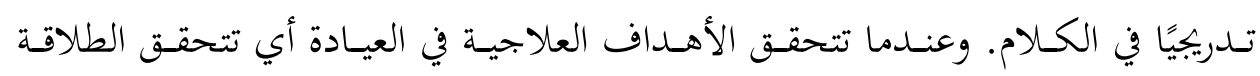

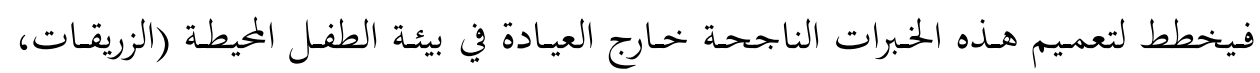

\section{تأخير التغذية السمعية المرتدة (Delayed Auditory Feedback):}

ذكر (B.S. Lee) Borsel, Sierens \& Medeiros, (2007) هو أول من أختبر تأثير تأخير التغذية السمعية المرتدة على طلاقة الأشخاص العاديين وذلك في عام (1950) وظهر من خلال ذلك تأثير واضح تسبب في ظهور مشكلات في الكلام

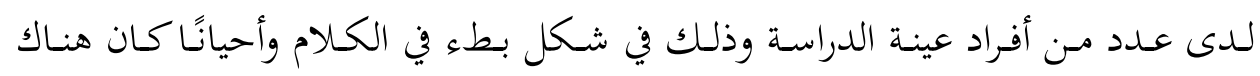

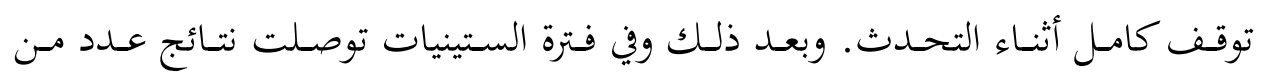

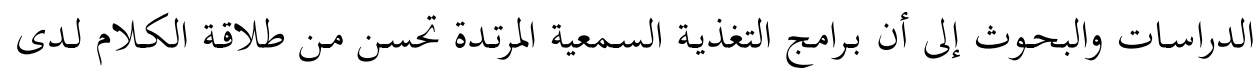


الأفراد المتلعثمين. وحديثًا هناك بعض الأدلة على فاعلية استخدام استراتيجية تأخير التغذية السمعية المرتدة في علاج التلعثم وهذا ما أكدته دراسة (الادل (Stuart \& Kalinowski, 2004).

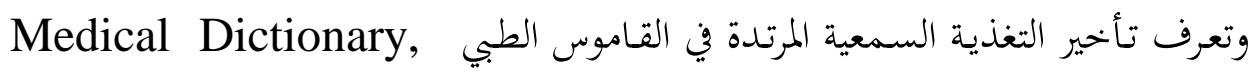

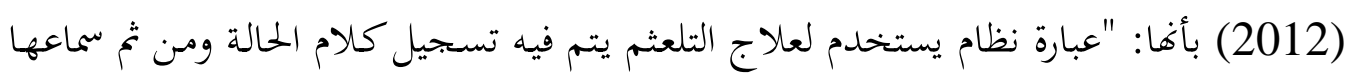

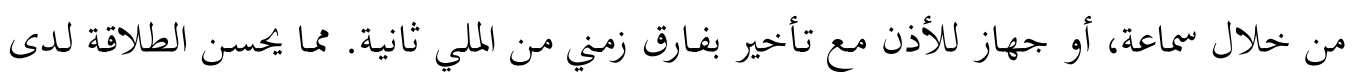
علد من المتلعثمين". وعرف (Borsel, Sierens \& Medeiros, (2007) تأخير التغذية السمعية المرتدة

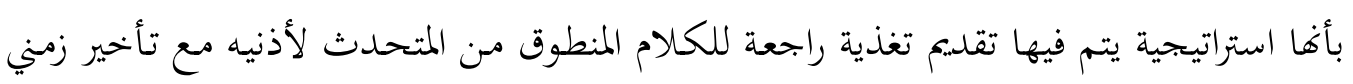

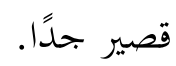

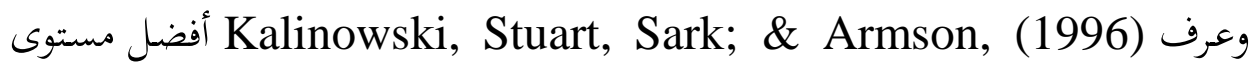

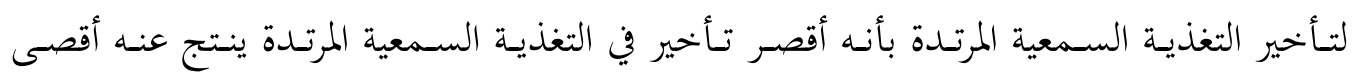

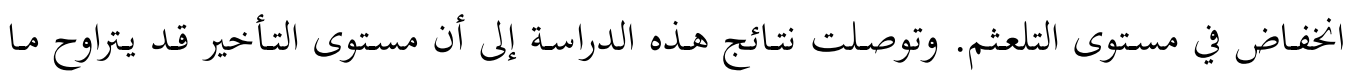

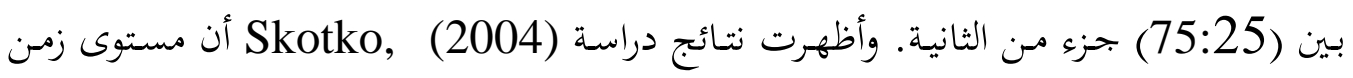

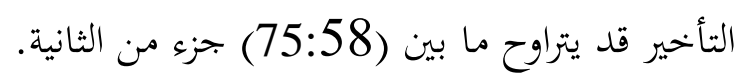

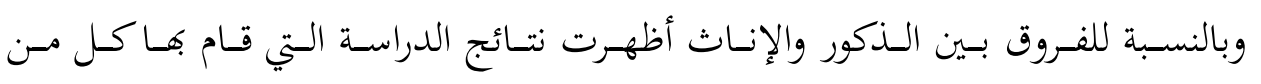

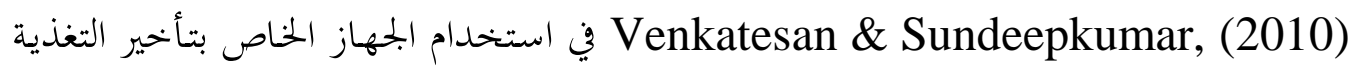
السمعية المرتدة أن الذكور كانوا أكثر تلعثمًا من الإناث بعد استخدام الجهاز . وأيضا أظهرت

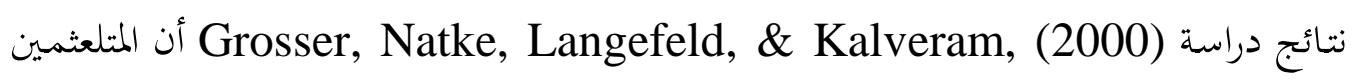
من الذكور أظهروا تأخر واضح في الكلام مقارنة بالإناث عند تطبيق برنامج لتأخير التغذية ألتانية السمعية المرتدة عليهم.

التقنيات المساندة لثأخير التغذية السمعية المرتدة:

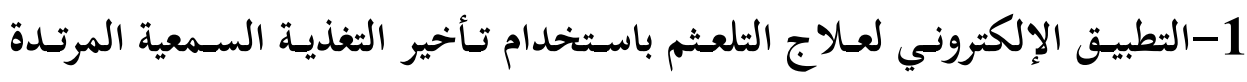

(Stuttering Therapy DAF) 
هو عبارة عن برنامج خحاص بتطبيقات الجموال يستخدم للأغراض الإرشادية ولا

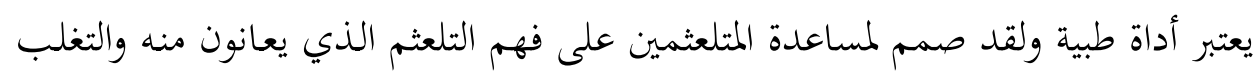
عليه باستخدام تأخير زمن التغذية السمعية المرتدة.

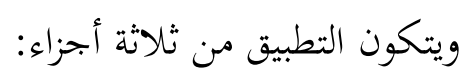

(أ) مؤقت للساعة: وقد يكون هذا التطبيق مفيدًا إذا استخدمه المتلعثم بمعدل 20 ونداء دقيقة كل يوم ولذا فهذا التطبيق مزود بمؤقت للساعة.

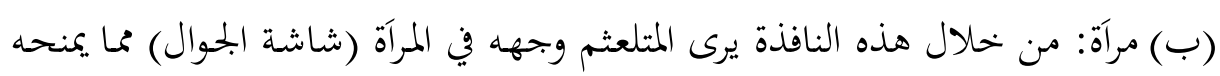
التحكم في المصاحبات الجسمية التي تظهر على وجه المتلعثم.

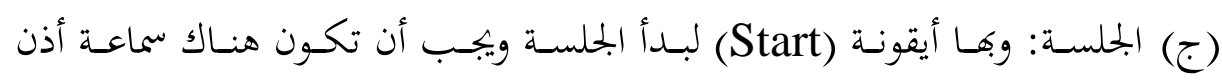

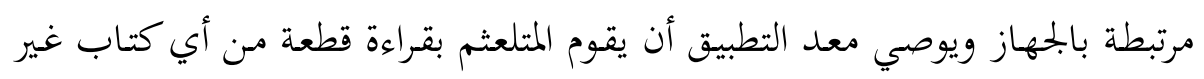
محبب للمتلعثم لمدة 20 دقيقة بزمن تأخير من 25 ملي ثانية إلى ثانية كاملة. وفيما يلي النافذة الخاصة بتطبيق (Stuttering Therapy DAF):

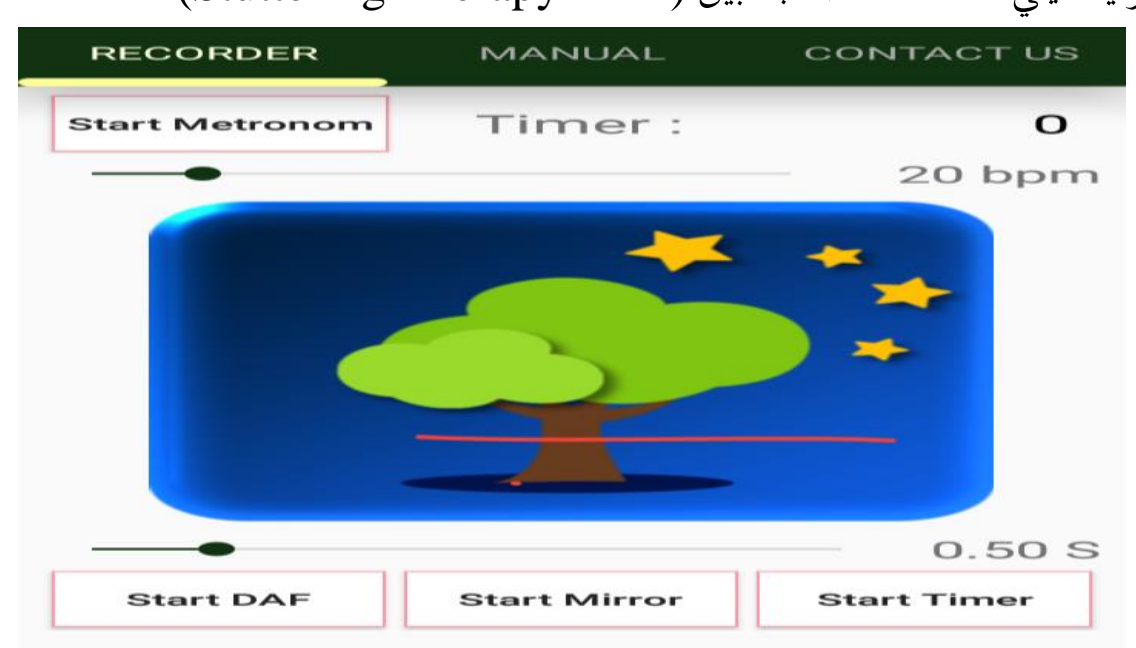

2-تطبيق المساعد للتلعثم (Stuttering Help): 
يبدأ التطبيق بتوضيح ذكر أن من المتفق عليه علميًا منذ فترة طويلة أن الاشخاص الذين يعانون من التلعثم قد يستطيعون التحدث بطلاقة عن طريق العلاج بتأخير التغذية السمعية المرتدة وذلك عن طريق عدم سماع أنفسهم عند التحدث. وفيما يلي نافذة تطبيق(Stuttering Help):

SELECT MODE

Off

DAF

Music

It has long been recognised that people who stutter can speak fluently when their auditory feedback is blocked so they cannot hear themselves talking.

\section{LISTENING MODE}

\section{Proximity}

\section{Speech (beta)}

The background music would be active whenever you start speaking and will be inactive when you stop speaking. This is in beta mode, so you might experience some difficulties.

\section{MUSIC MODE INFO}

Please make sure your music player is running in the background for the music to play. 
وهو جهاز صغير جـاًا يشبه المعينـات السمعية كسماعة الأذن ولكنه قائم على عملية تأخير التغذية السمعية المرتدة ويستخدم ضمن التقنيات المساندة لعلاج التلعثم. SpeEcheasy.

\section{The Technology}

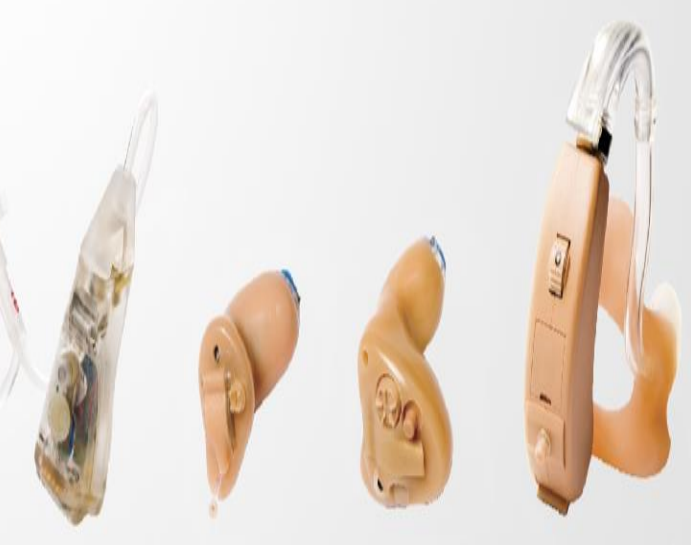

(SmallTalk DAF device) جهاز

وذكر موقع الجهاز بأنه عبارة عن جهاز صغير يقلل من مستوى التلعثم بسرعة

كبيرة ويستمر التدريب على الجهاز لفترة حتى يتم الاستغناء عنه والتحدث بطلاقة طبيعية

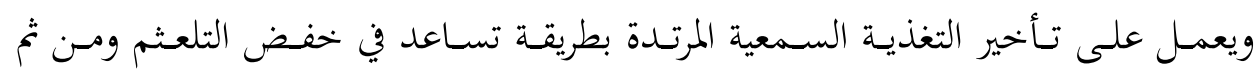

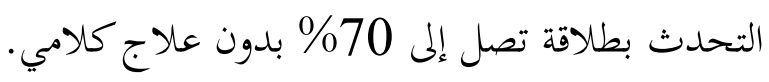




\section{صورة لجهاز)(SmallTalk DAF device)}

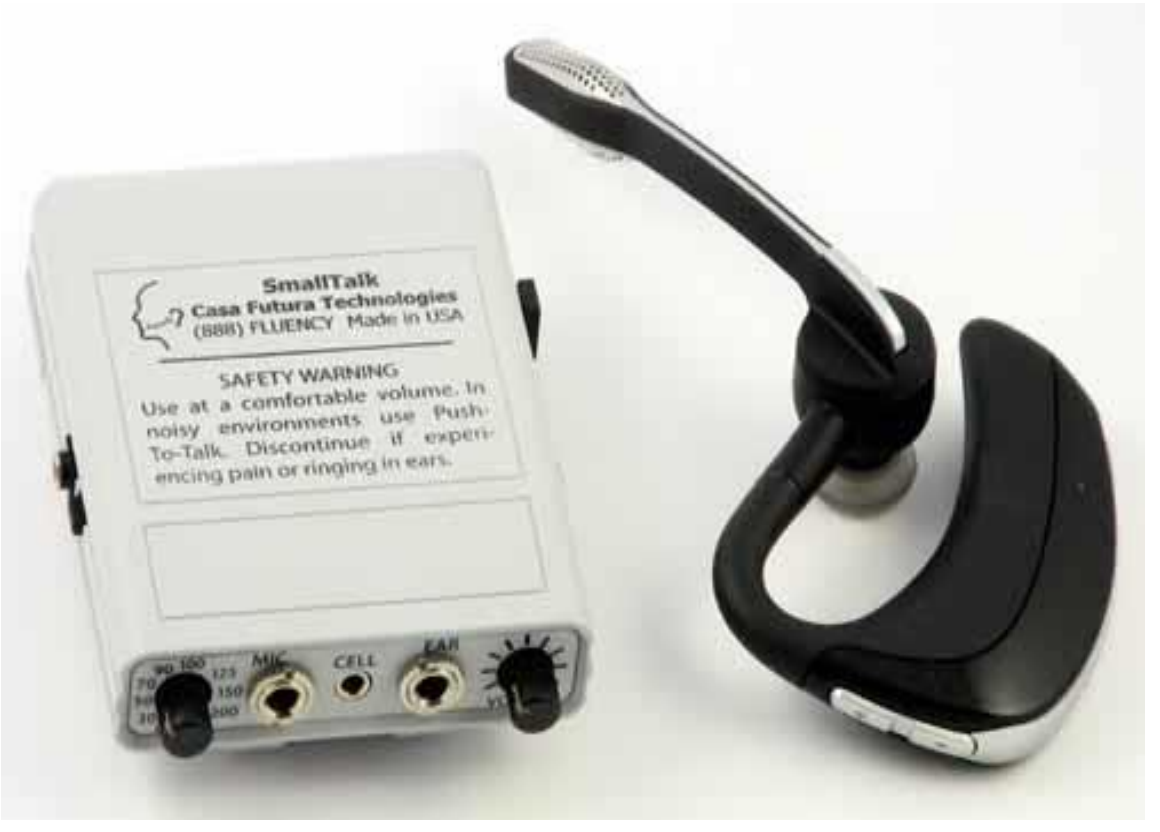

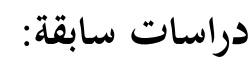

هدافت دراسة (2018) : إلى التحقق من استخدام تطبيق خاص بالجوال في

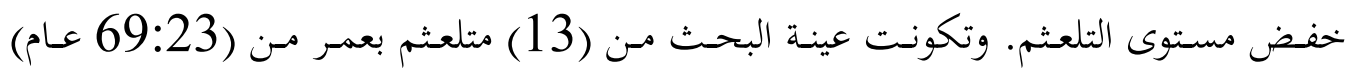

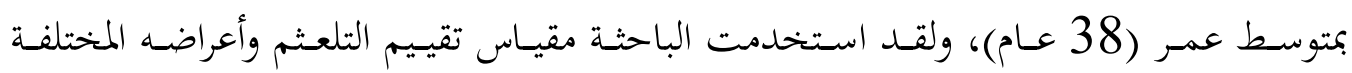

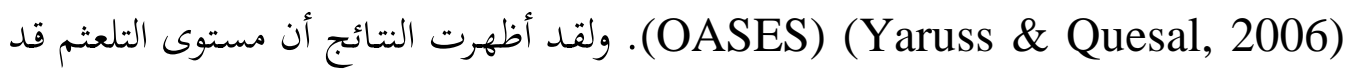

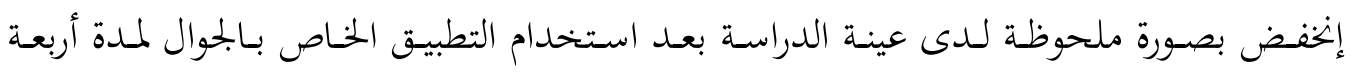
أسابيع.

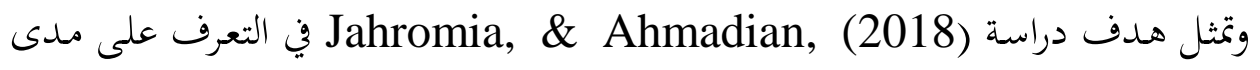

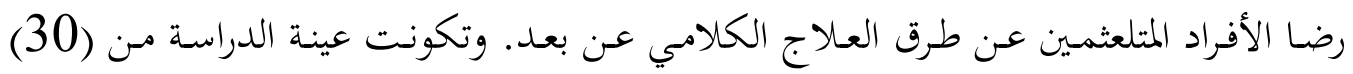

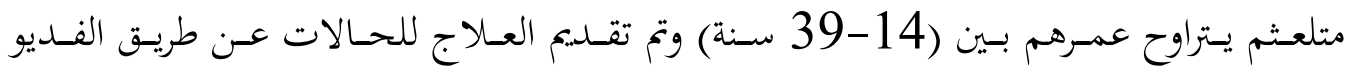

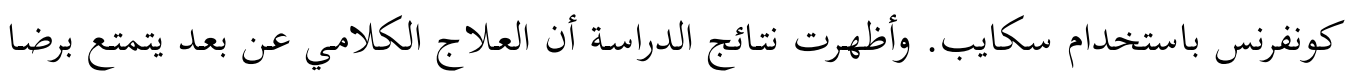


واضح لدى الأفراد المتلعثمين. وليس هناك فروق بين الذكور والأناث في الرضا عن العلاج الكلامي عن بعد. ولا توجد علاقة بين مستوى التعلم والعمر والعلاج الكلامي عن بعد.

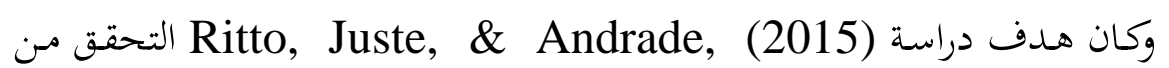

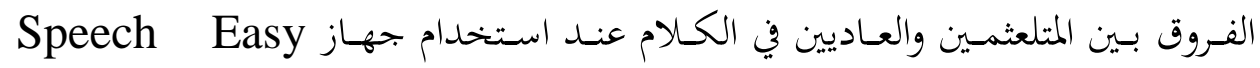
وتكونت عينة البحث من (20) فرد بعمر يتراوح بين (12-40 عـام) بمتوسط عمر فئر

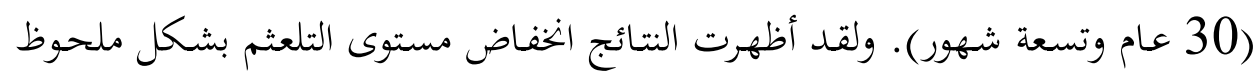

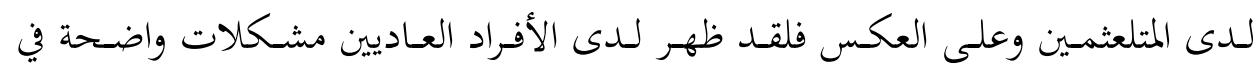

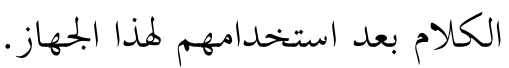

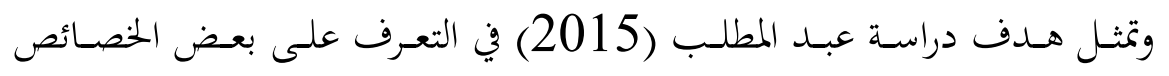
النفسية والشخصية لدى طلاب المرحلة الثانوية بدولة الكويت المصابين باضطراب التلعثم

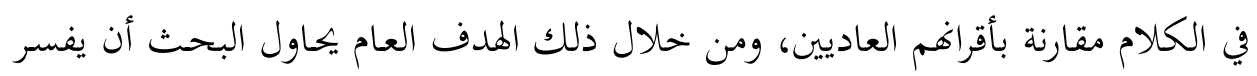

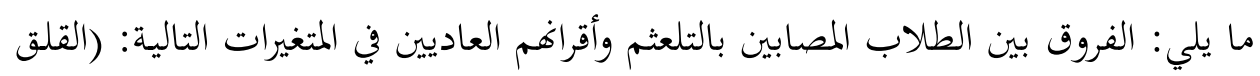

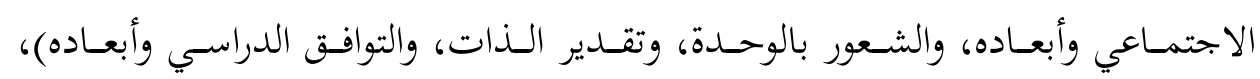

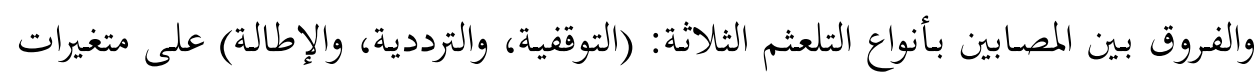

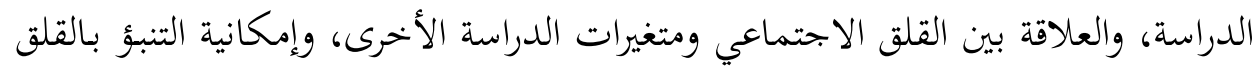

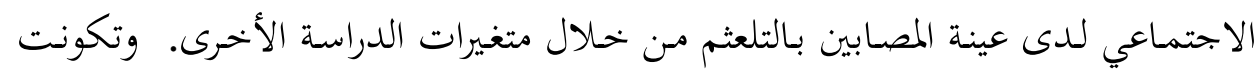

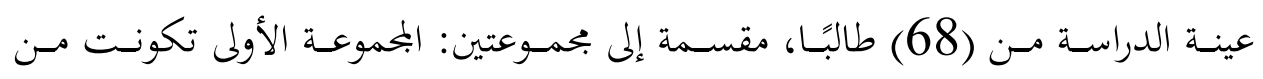

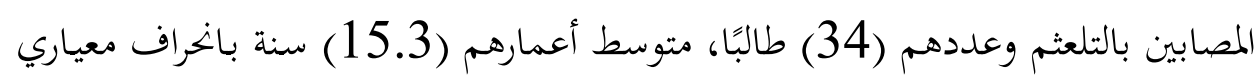

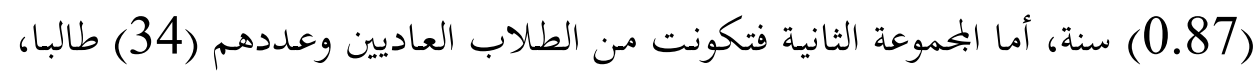

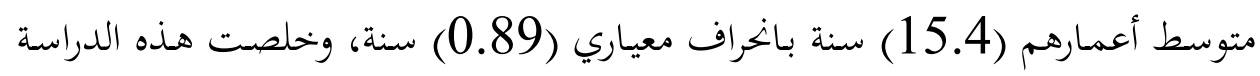
إلى النتائج التالية: وجدود فروق بين المجموعتين على مقياسي القلق الاجتماعي وأبعاده

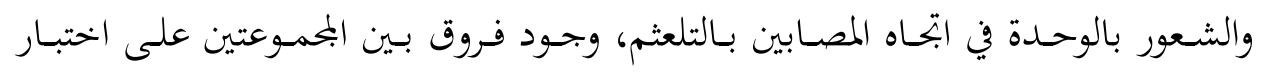

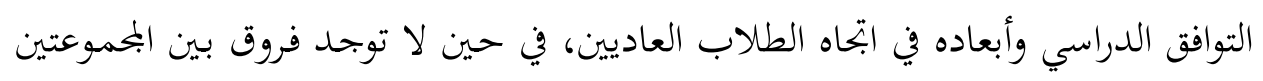


على مقيـاس تقــير الذذات، كمـا توجـــ علاقة ارتباطية سـالبة بين القلق الاجتمـاعي والتوافق الدراسي، بالإضافة إلى وجود علاقة ارتباطية سالبة بين الشعور بالوحدة وتقدير الذات لدى عينة

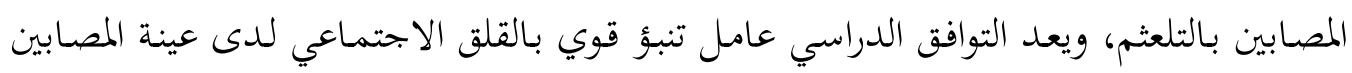
بالتلعثم.

وهـدفت دراسة (Weigel,2013) إلى التعرف على الأسباب التي تساهم في العلاج

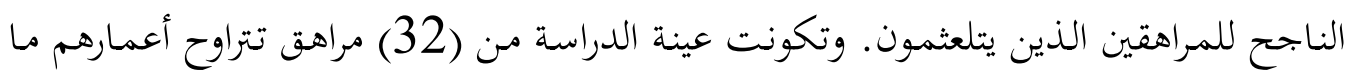

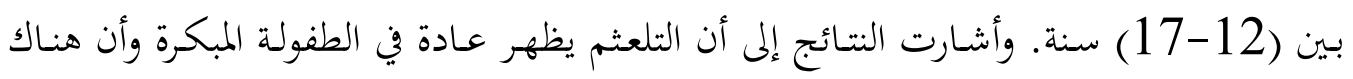

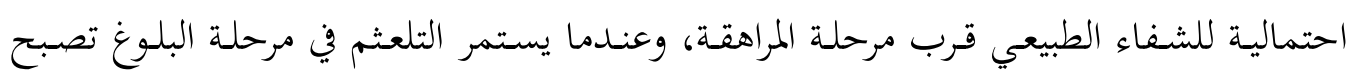

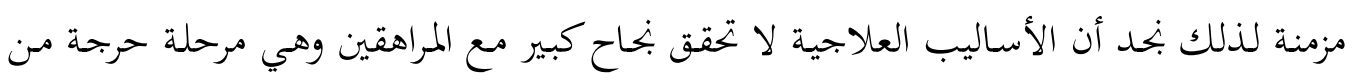

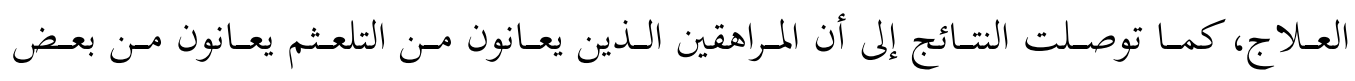

$$
\text { الاضطرابات النفسية (مثل الخوف- القلق - الانطواء- الخجل). }
$$

وقدم (Bahadorinejad and Almasganj, 2012) طريقة مبتكرة لطرق علاج التعلثم بزمن التأخير للتغذية السمعية المرتدة (25 - 75 ملي / ثانيـة) في تصميم نظام تقني

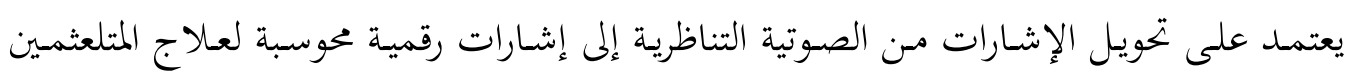
عن طريق تخفيف الضغوط التي يسببها التلعثم.

وكشفت دراسة (Cook, 2009) عن مستوى الطلاقة الكلامية لدى (10) متلعثمين من الذكور المستخدمين جهاز Speech Easy لمدة عام، وذلك من خحلال تحليل استجاباقم

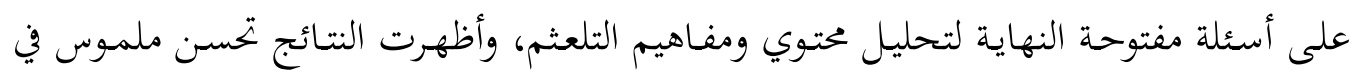
مستوى المشاركات الكلامية للعينة، وتحين مستوى طلاقتهم الكلامية.

مقترح رباعي الأبعاد لتشخيص وعلاج التلعثم إعداد الباحث: من خلال العرض السابق للجانب النظري لتعريف وتشخيص وعلاج التلعثم والدراسات السابقة يقدم الباحث مقترح رباعي الأبعاد لتشخيص وعلاج التلعثم. 


$$
\text { 1 - تشخيص التلعثم: }
$$

في هذه المرحلة يعتمد التشخيص على خطوات أربع تبدأ من التشخيص العضوي

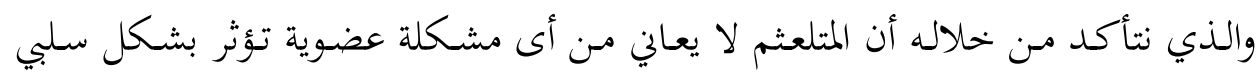

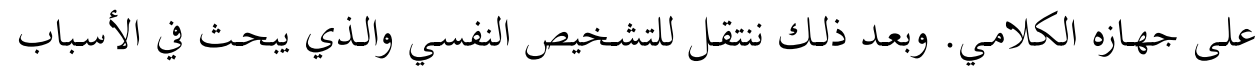

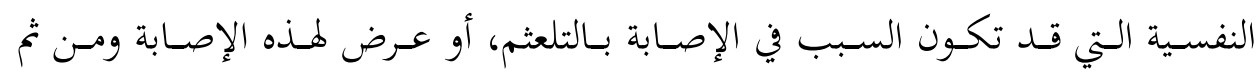

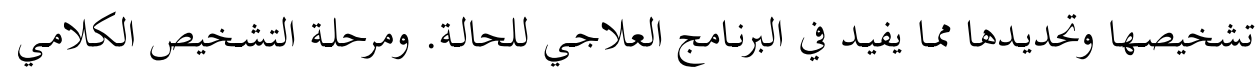
تحدد مدى شدة الإصابة وتقف على مظاهر التلعثم التي تنتشر عند المتلعثم. وفي النهاية

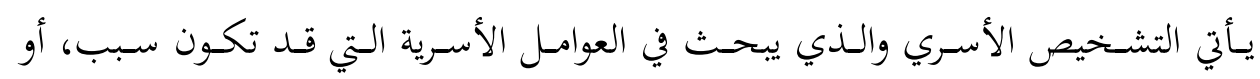

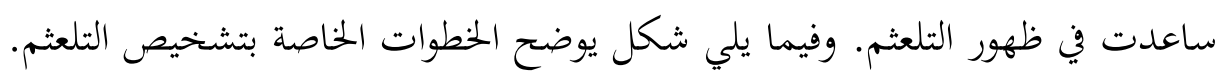

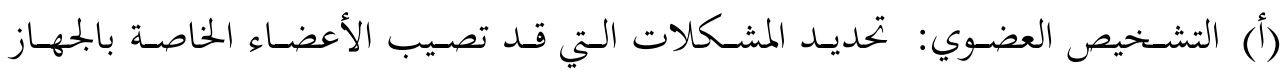
الكلامي. • الأعضاء التي تسهم في إخراج الكلام (تبدأ من الرئتين وتنتهي بالشفتين).

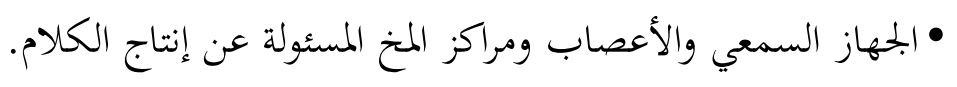

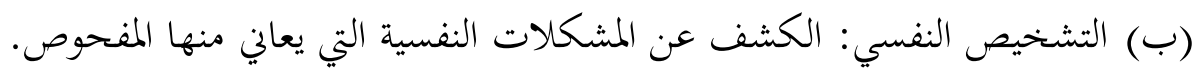

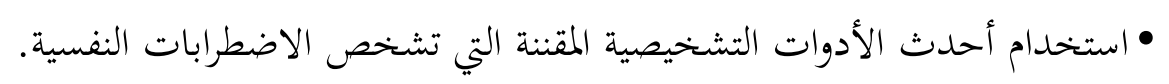
• القيام بدراسة حالة للمفحوص.

(ج)التشخيص الكلامي: تحديد الاضطراب الكلامي الذي يعاني منه المفحوص.

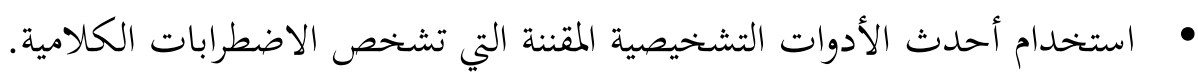
• تحديد محتوى ومدى شدة هذا الاضطراب.

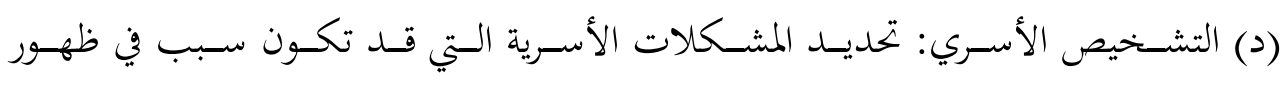
الاضطرابات.

• • الكشف عن مسببات الاضطراب الخاصة بتعامل الأب والأم (كالعقاب، أو التدليل). علاقة الأم والأب والإخوان وأيضا الأقارب بالمفحوص. 


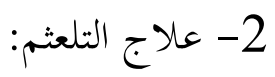

في هذا المقترح يتضمن عـاج التلعثم أربعة أشكال مـ العلاج تتكامل وتساند بعضهـا

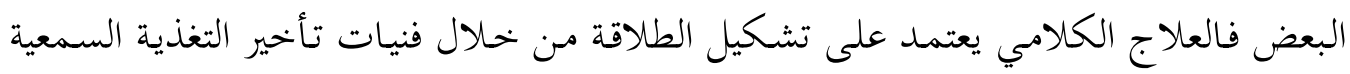

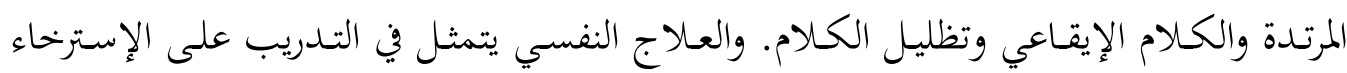

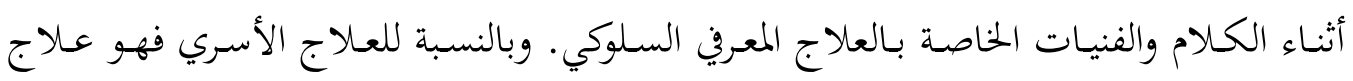

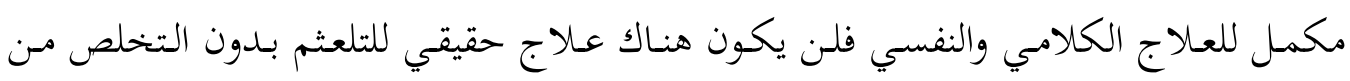

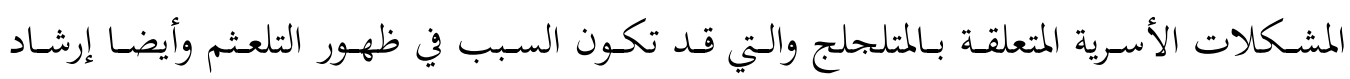

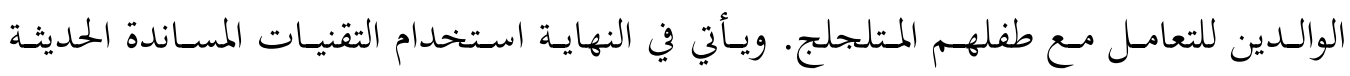

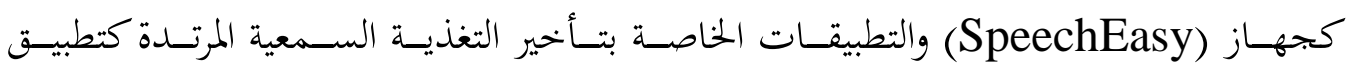
كأساليب تكنولوجية حديثة قد تساعد في خفض التلعثم. (Stuttering Therapy DAF)

\section{توصيات البحث:}

التلعثم مشكلة معقدة مركبة تحتاج إلى تدخلات علاجية مختلفة تتناسب مع كل حالة من

$$
\text { حالات التلعثم ومن التوصيات في هذا الموضوع ما يلي: }
$$

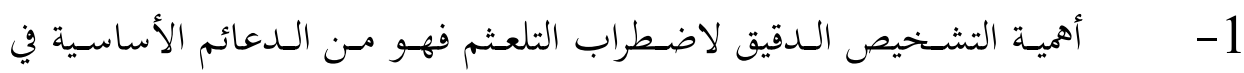

$$
\text { إعداد برنامج ناجح في علاج التلعثم. }
$$

2- - - من الضروري وضع خطة علاجية دقيقة قائمة على تشخيص واقعي للحالة.

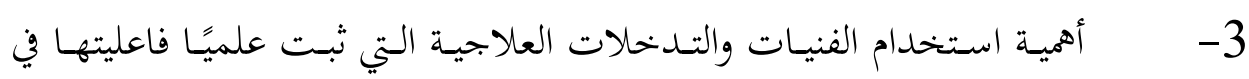

$$
\text { علاج التلعثم. }
$$

5- الإعتماد على بعض تطبيقات الجحوال الحديثة التي ثبت قدرها على المساندة

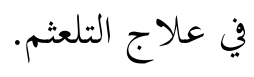




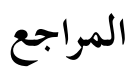

$$
\begin{aligned}
& \text { أمين، سهير محمود (2000). اللجاعة أسباجا وعلاجها. القاهرة: دار الفكر العربي. } \\
& \text { باظهه، أمـال عبـد السـميع (2003). اضطرابات التواصل وعلاجهـا ـ. القـاهرة: مكتبـة الأبحلو } \\
& \text { المصرية. }
\end{aligned}
$$


براده، هدي عبد الحميد وصادق، فاروق محمد (2000). علم نغس النمو. وزارة التربية والتعليم

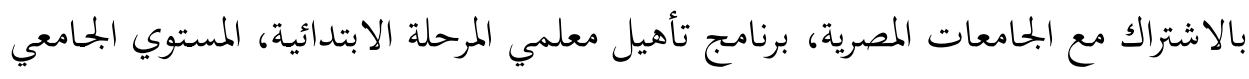
القاهرة : دار الشرق الأوسط للنشر.

الببلاوي، إيهاب عبد العزيز (2016). اضطرابات التواصل (ط7). الرياض: دار الزهراء.

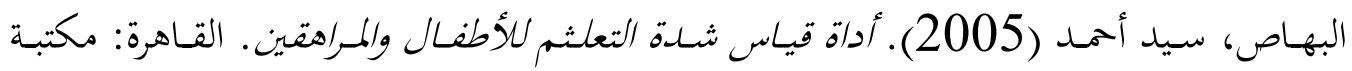

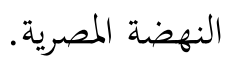

جبريل، فاروق و شعبان، عرفات (2007). تقدير الذات والمهارات الاجتماعية لدى الأطفال

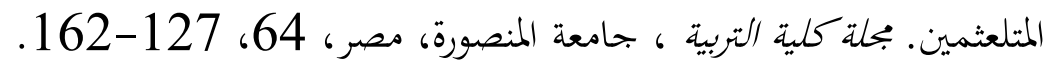

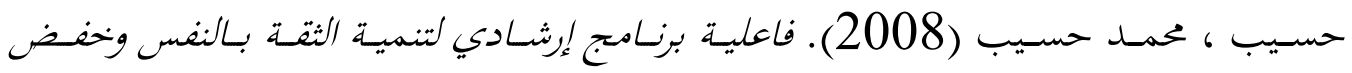

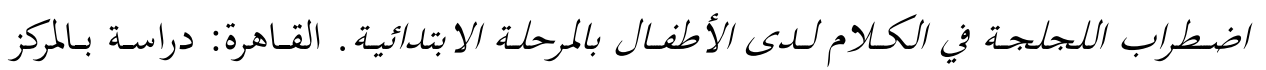
القومي للامتحانات والتقويم التربوي.

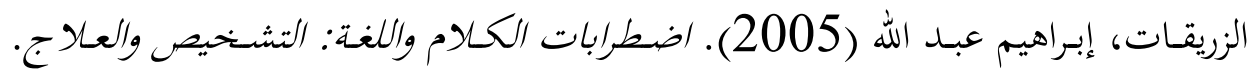
عمان: مار الفكر.

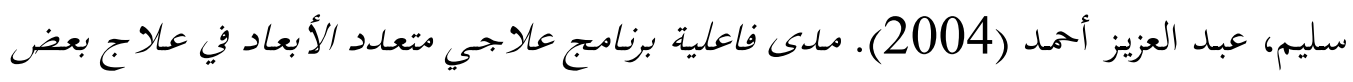
حالات اللجلجة للدى عينة من تلاميذ المرحلة الابتدائية . رسالة ماجستير غير منشورة، كلية التربية بدمنهور، جامعة الإسكندرية. الشخص، عبد العزيز السيد (1997). اضطرابات النطق والكملام: خلفيتها- تشخيصهاأنواعها- علاجها. الرياض: مكتبة الصفحات الذهبية.

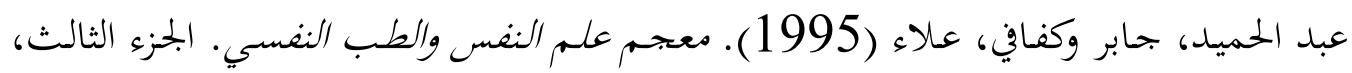
القاهرة: دار النهضة العربية.

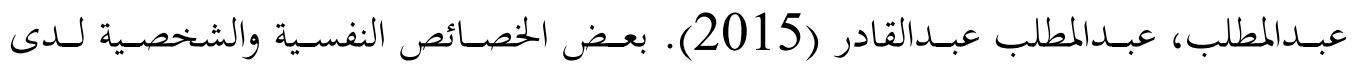

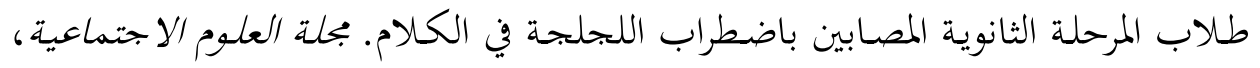
الكويت، 43(2)، 11- 11 (21. 


$$
\begin{aligned}
& \text { عيد، يوسف محمد (2010). بطارية كلامية نغسية. القاهرة: مكتبة الأنحلو المصرية. }
\end{aligned}
$$

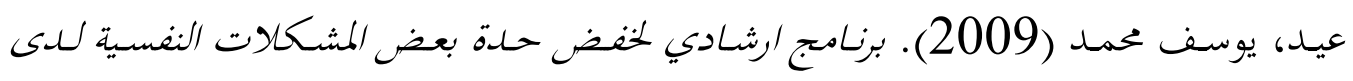

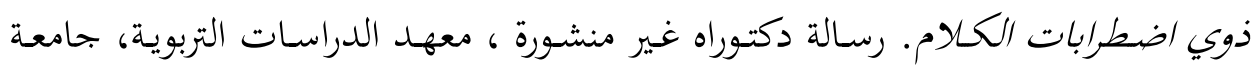

$$
\begin{aligned}
& \text { القاهرة. } \\
& \text { العطية ، أسماء (2011). أثر برنامج خفض مستوى اللجلجة وتشكيل الطلاقة اللفظية لدى }
\end{aligned}
$$

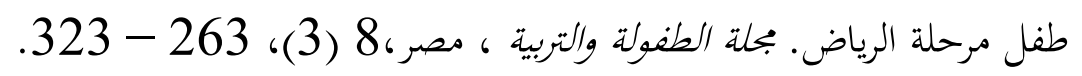

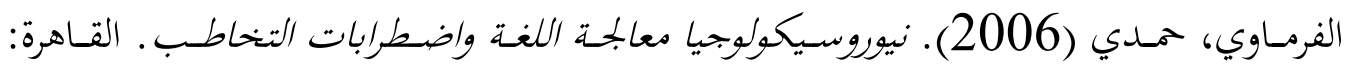

$$
\begin{aligned}
& \text { مكتبة الأنجلو المصرية. } \\
& \text { كاشف، إيمان (2005). فعالية برنامج إرشادي لخفض القلق لدي عينة من الأطفال المتلعثمين }
\end{aligned}
$$

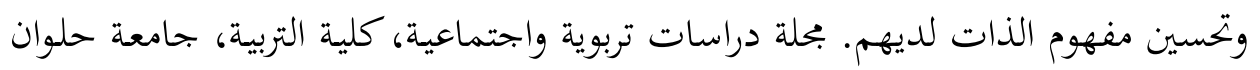

$$
\begin{aligned}
& \text { 11 } 11
\end{aligned}
$$

Andrade, C. (2003). Speech therapy program for promoting stuttering adults: treatment and maintenance. Speech therapy: Information for training - therapeutic procedures in language. Rio de Janeiro: Guanabara Koogan, 27-53.

Bahadorinejad A., and Almasganj F.(2012). Delayed auditory feedback for speech disorders, IEEE International Conference on Biomedical Engineering (ICoBE), Penang, 27-28 February 2012.

Bloodstein,O. (2007). A handbook on stuttering.Chicago: National Easter seal society.

Borsel, Sierens and Medeiros (2007). Using delayed auditory feedback in the treatment of stuttering. Pró-Fono R. Atual. Cient, 19 (3), Barueri Sept . 2007.

Chesters,J.,Mottonen,R, Watkins,K. (2018). Transcranial direct current stimulation over left inferior frontal cortex improves speech fluency in adults who stutter. Brain,141(4),1161-1171.

Coleman,C (2018). Comprehensive Stuttering Treatment for Adolescents: A Case Study. Language, Speech, and Hearing 
Services in Schools, 49, 33-41. doi:10.1044/2017_LSHSS-170019

Cook, M. (2009). Outcomes for adult males using the Speech Easy RTM fluency device for one year, Southern Illinois University at Carbondale, Ph. D Thesis, AAT 3390846.

Diagnosis and Statistical Manual of Mental Disorder (DSM-V) (2013). American Psychiatric Association,5th.

Freiterg, Karen L. (2002). Human development: Life - span approach. (4 ${ }^{\text {th }}$ Ed.). Boston. London. Jones and Bantlett Publishers.

Grosser, Natke, Langefeld, Kalveram (2000). Reduction in stuttering by delayed and frequency shifeted auditory feedback: effect of adaptation and sex differences. J. Fluency Dis., Autumn,. 25(3), 252-252.

Gully,(2018). Measuring the effects of prosthetic tactile Pacing on overt Stuttering Frequency in Adults who stutter. A thesis submitted to the faculty of The University of Mississippi, University, MS,May 2018.

Jahromia,M, Ahmadian,L (2018). Evaluating satisfaction of patients with stutter regarding the tele-speech therapy method and infrastructure. International Journal of Medical Informatics, $115,128-133$.

Kalinowski , J.; Stuart, A.; Sark, S.; Armson, J.(1996). Stuttering amelioration at various auditory feedback delays and speech rates. Europ. J. Dis. Commun., 31 (3), 259-269.

Kalinowski,JS(2006). Stuttering, San Diego: Plural Publishing, 3137.

Kirk, S., Gallagher, J. , Coleman, M. and Anastasiow, J. (2006). Education exceptional children. New York: Houghton Mifflin company.

Medical Dictionary(2012). definition of delayed auditory feedback by Medical dictionary for the Health Professions and Nursing (C) Farlex 2012.

Riper, Van (2009). Speech correction: principles and methods. 7th Ed. N.J. Prentice- Hall. Englewood Cliffs. 
Ritto,A, Juste,F, Andrade,C (2015). The effect of the SpeechEasy® device on acoustic and speech motor parameters of adults who stutter. Audiology - Communication Research ,20 (1), http://dx.doi.org/ 10.1590/S2317-64312015000100001440.

Skotko, J.(2004). Experience of a speech pathologist providing clients with the SpeechEasy ${ }^{\mathrm{TM}}$ device. Stammering Res.1, $1(1), 63-65$.

Stuart , A.; Kalinowski , J.(2004). The perception of speech naturalness of post-therapeutic and altered auditory feedback speech of adults with mild and sever stuttering. Folia Phoniatr. Logopaedica, Basel, 56 (6), 347-357.

Venkatesan, M. \&Sundeepkumar,S. (2010). The relationship between speech disfluencies produced under delayed auditory feedback and auditory processing skills in fluent speakers, East Tennessee State University, AAT 1486239.

Ward, David (2006). Stuttering and Cluttering: Frameworks for understanding treatment, Hove and New York City: Psychology Press, 5-6.

Weigel ,Megan(2013). Adolescents who stutter : perceptions of effective therapy techniques, M.A., Duquesne University. 